\title{
Опыт применения фенспирида в раннем реабилитационном периоде после перенесенной пневмонии у детей
}

\author{
1 - кафедра педиатрии № 1 Санкт-Петербургской медицинской академии последипломного образования: 193036, Санкт-Петербург, Суворовский пр-т, 4; \\ 2 - Детская городская больница № 19 им. К.А.Раухфуса: 191036, Санкт-Петербург, Суворовский пр-т, 4; \\ 3 - Детская городская поликлиника № 12: 196180, Санкт-Петербург, Загородный пр-т, 29; \\ 4 - Детская городская поликлиника № 8: 191123, Санкт-Петербург, ул. Чайковского, 73
}

\section{N.D.Soroka, E.V.Korshunova, S.P.Gomozova, T.G.Vlasova, V.N.Kotelnikova \\ The experience of use of fenspirid in the early rehabilitation period of community-acquired pneumonia in children}

\begin{abstract}
Summary
The paper contains data on morbidity of childhood community-acquired pneumonia (CAP) at Sankt-Petersburg and describes peculiarities of current clinical and radiological course of pneumonia. Recently, CAP in children tends to slowly resolving course. The necessity and rationality of the patients' follow-up after clinical resolution of pneumonia and the need in prolonged pathogenic therapy till the complete resolution of the inflammatory broncopuomonary process in ambulatory settings have been established. Results of the clinical study of efficacy of non-steroidal anti-inflammatory drug fenspirid (Eurespal) for treatment of residual pneumonic lesions and indications for the administration in 44 children of 9 months to 17 years of age were highlighted. A high efficacy of fenspirid was noted along with good safety profile. There was no interaction between fenspirid and other drugs used in treatment of childhood pneumonia.

Key words: children, respiratory disease, community-acquired pneumonia, anti-inflammatory therapy, fenspirid.
\end{abstract}

\section{Резюме}

В статье представлены данные о заболеваемости пневмонией среди детского населения Санкт-Петербурга, определены особенности современного клинико-рентгенологического течения патологии. Выявлена склонность к затяжному течению бронхолегочного процесса у детей. Доказаны целесообразность диспансерного наблюдения после клинического завершения заболевания и необходимость патогенетического лечения до полного завершения бронхолегочного процесса в амбулаторных условиях. Обосновано применение и представлены данные клинического исследования эффективности нестероидного противовоспалительного препарата Эреспал (фенспирид) в лечении остаточных пневмонических изменений у 44 детей в возрасте от 9 мес. до 16 лет. Показана высокая эффективность фенспирида при высоком профиле безопасности. Не выявлено лекарственного взаимодействия с другими препаратами, применяемыми в комплексном лечении пневмонии у детей.

Ключевые слова: дети, заболевания органов дыхания, амбулаторная пневмония, противовоспалительная терапия, фенспирид.

Внебольничная пневмония (ВП) - одно из наиболее частых инфекционных заболеваний в детском возрасте. Благодаря успехам последних лет, достигнутым в вопросах диагностики и лечения ВП у детей, изменилось ее течение, существенно уменьшилось число тяжелых форм болезни с катастрофическим течением, снизилась летальность. Однако актуальность данной проблемы сохраняется, распространенность заболевания все еще достаточно высока, и, несмотря на то, что ВП принято относить к управляемым инфекционным заболеваниям, летальность регистрируется ежегодно.

По данным медицинской статистики, в структуре болезней органов дыхания у детей Санкт-Петербурга доля ВП составляет $6 \%$, причем за последние 15 лет показатель практически не изменился, составляя в среднем 5,6 на 1000 среднегодового детского населения и соответствуя данным начала 90-х гг. XX в. Динамика показателей заболеваемости ВП среди детей Санкт-Петербурга (за 1992-2008 гг.) представлена на рис. 1 [1].

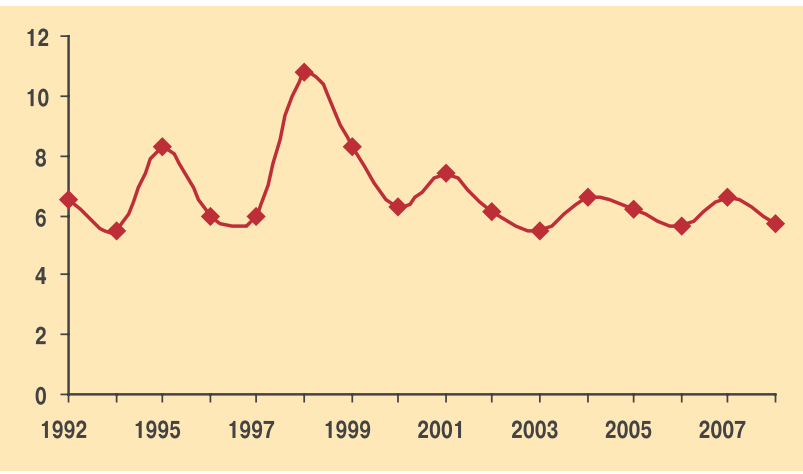

Рис. 1. Динамика заболеваемости ВП детского населения СанктПетербурга (1992-2008 гг.)

Несмотря на относительно скромный удельный вес ВП в структуре заболеваний детского возраста, пневмония всегда относилась к социально значимым патологиям, какой считается и в настоящее время. Актуальность проблемы пневмонии очевидна и обусловлена следующими факторами: 
- высокой распространенностью среди детского населения;

- тяжестью течения (пневмония не имеет легких вариантов течения);

- высокой потребностью в госпитализации (только в 2008 г. в Санкт-Петербурге было необходимо госпитализировать 45 \% детей с ВП);

- риском хронизации бронхолегочного процесса и инвалидизации ребенка в случаях тяжелого, осложненного, деструктивного пневмонического процесса;

- сохраняющейся летальностью;

- ростом стоимости лечения, связанным, прежде всего, с проблемой нарастающей резистентности к традиционным антибактериальным препаратам ведущих пневмотропных патогенов.

Анализируя особенности ВП у детей, следует отметить тенденцию к затяжному течению заболевания. По данным Детского городского пульмонологического центра (Санкт-Петербург) длительный, вялотекущий бронхолегочный процесс наблюдается более чем у 30 \% пациентов с ВП, и именно такой характер течения наиболее типичен для большинства часто болеющих детей, имеющих неблагоприятный преморбидный фон или сопутствующие коморбидные заболевания [1].

Полностью клинически и / или рентгенологически пневмонический процесс по окончании антибактериальной терапии не завершается у подавляющего большинства детей, что диктует необходимость продолжать лечение и проводить достаточно интенсивные лечебные мероприятия.

Выбирая методы и способы лечения ребенка в раннем реабилитационном периоде ВП, нередко приходится решать вопрос о необходимости и целесообразности проведения дополнительного курса антибиотикотерапии в связи с наличием отдельных сохраняющихся остаточных проявлений ВП, свидетельствующих о незавершенности воспалительного процесса в бронхолегочной системе. Однако многочисленные исследования по антибактериальному лечению ВП в последнее время свидетельствуют о целесообразности и достаточности для достижения клинического эффекта и эрадикации возбудителя заболевания 1 курса эмпирически адекватно подобранного (с учетом тяжести течения, преморбидного состояния пациента и пр.) антибактериального препарата.

Рекомендуемая продолжительность антибиотикотерапии нетяжелой ВП для большинства препаратов обычно составляет 7-10 дней. Антибактериальная терапия может быть завершена при стойкой нормализации температуры тела на протяжении 3-4 дней [2].

Показаниями к завершению антибактериального лечения могут служить:

- нормализация температуры;

- отсутствие симптомов интоксикации;

- отсутствие проявлений дыхательной недостаточности;

• прекращение экспекторации гнойной мокроты;
- положительная динамика гематологических показателей активности воспалительного процесса (лейкоцитоз $<10 \times 10^{9} /$ л, юных форм $<6 \%$ );

- отсутствие инфильтративно-пневмонических изменений и / или наличие остаточных пневмонических изменений на рентгенограмме.

Известно, что запущенный причинно значимым возбудителем воспалительный процесс при ВП не заканчивается эрадикацией возбудителя: заболевание, как правило, переходит в фазу функционального и морфологического восстановления и период реконвалесценции. На этом этапе может потребоваться противовоспалительное лечение до полного завершения воспаления в легочной паренхиме, т. к. остаточные пневмонические изменения могут быть причиной рецидивов и хронизации бронхолегочного процесса [3].

Именно в ранний период реконвалесценции после завершения антибактериальной терапии крайне целесообразно проведение активной противовоспалительной терапии, не имеющей побочных эффектов, характерных для антибиотиков, не повреждающей симбионтную микрофлору организма. Современная противовоспалительная терапия должна быть направлена на снижение проявлений интенсивности уже запущенной воспалительной реакции путем блокады выработки медиаторов воспаления. Доказано, что именно неконтролируемая продукция провоспалительных цитокинов и их концентрация в слизистой оболочке дыхательных путей может играть решающую роль в морфологической перестройке эпителия дыхательных путей, имеющей ведущее значение в хронизации воспалительного процесса $[4,5]$.

Из современных нестероидных противовоспалительных препаратов наиболее предпочтительным для лечения ВП в период ее ранней реконвалесценции является Эреспал (фенспирид). Он зарегистрирован и применяется в РФ с 1998 г., имеет доказанное в многочисленных клинических испытаниях, проведенных как в нашей стране, так и за рубежом, многоплановое патогенетическое влияние на узловые моменты воспаления. В клинических испытаниях и экспериментально установлено, что противовоспалительный эффект фенспирида по механизму действия близок к кортикостероидам, однако препарат лишен многочисленных побочных явлений, характерных для стероидной терапии и, прежде всего, не влияет на функцию системы "гипоталамус - гипофиз - кора надпочечников". Основой противовоспалительного воздействия фенспирида является блокада транспорта в клетки ионов кальция, необходимых для активации ключевого фермента - активатора каскада арахидоновой кислоты (фосфолипазы А2). Блокада активации арахидонового цикла препятствует выработке основных провоспалительных метаболитов арахидоновой кислоты - лейкотриенов и простагландинов.

К противовоспалительным фармакологическим эффектам фенспирида относятся:

- воздействие на сосудистый и клеточный компонент воспаления, результатом которого является 
уменьшение проницаемости сосудистой стенки, ограничение экссудации и отека;

- частичная блокада $\alpha_{1}$-адренорецепторов, уменьшающая гиперпродукцию слизи;

- спазмолитический эффект за счет влияния на гладкую мускулатуру бронхов, способствующий улучшению бронхиальной проходимости;

- антагонистическое действие на $\mathrm{H}_{1}$-гистаминовые рецепторы, снижающее синтез и ингибирующее действие гистамина, а также блокирующее увеличение объема бронхиальной секреции;

- ограничение лейкоцитарной инфильтрации;

- снижение интенсивности экссудативного воспаления и, как результат этого процесса, косвенное влияние на его основные клинические проявления со стороны бронхолегочной системы (кашель, экспекторацию мокроты, бронхообструктивный синдром и пр.) [5-7].

В настоящее время доказана высокая клиническая эффективность фенспирида в лечении практически всех заболеваний верхних дыхательных путей, различных клинических вариантов бронхитов, обострений хронической обструктивной болезни легких. В данном исследовании препарат применяли в терапии остаточных воспалительных изменений в бронхолегочной системе после окончания курса антибиотикотерапии при ВП у детей.

С целью оценки клинической эффективности нестероидного противовоспалительного препарата фенспирид в комплексном лечении раннего реабилитационного периода ВП у детей проведено открытое многоцентровое исследование на базе Детской городской клинической больницы им. К.А.Раухфуса и ряда городских детских поликлиник Санкт-Петербурга.

\section{Материалы и методы}

В исследовании участвовали 44 ребенка в возрасте от 9 мес. до 16 лет (25 мальчиков и 19 девочек) с ВП, у которых после завершения курса антибактериальной терапии имелись клинико-рентгенологические и лабораторные признаки остаточных пневмонических изменений, т. е. не полностью завершенный бронхолегочный процесс. Все пациенты наблюдались и лечились в зимне-весенний период 2008 г. в лечебно-профилактических учреждениях СанктПетербурга: 45 \% были выписаны после завершения антибактериальной терапии из стационаров города и продолжали лечение в амбулаторных условиях, 55 \% изначально наблюдались по поводу ВП в амбулатор-

Таблица 1 Возрастной состав детей, включенных в исследование эффективности фенспирида

\begin{tabular}{|c|c|}
\hline Возраст, лет & $n(\%)$ \\
\hline$<1$ & $2(4,5)$ \\
\hline $1-5$ & $18(40,9)$ \\
\hline $6-10$ & $14(31,8)$ \\
\hline$\geq 11$ & $10(22,8)$ \\
\hline Bcero & $44(100,0)$ \\
\hline
\end{tabular}

ных условиях. Из исследования были исключены дети с тяжелыми фоновыми заболеваниями, такими как сахарный диабет, болезни сердца, печени, почек и других органов, а также тяжелыми, сопровождающимися функциональными расстройствами болезнями органов дыхания (деструктивными, хроническими, генетически детерминированными, врожденными, системными и пр.).

Среди испытуемых преобладали дети дошкольного и школьного возраста (старше 6 лет - 54,6 \%). Возрастной состав включенных в исследование пациентов представлен в табл. 1 .

Исследование проводилось по единому протоколу. Диагноз ВП у всех пациентов был документирован на основании типичных клинических проявлений, характерных лабораторно-воспалительных гематологических изменений и подтвержден рентгенологически.

По клинико-рентгенологическому варианту подавляющее большинство детей (72 \%) перенесли очагово-сливную бронхопневмонию с преимущественной локализацией пневмонического процесса в средней $(25 \%)$ и нижней $(20,5 \%)$ долях правого легкого; у 6,8 \% пациентов был 2-сторонний пневмонический процесс. Крупно-фокусные и сегментарные пневмонии диагностировались реже (28 \%), преимущественно у детей > 10 лет, с наиболее частой локализацией в базальных сегментах легких. Осложненное течение ВП (плевральная реакция, субсегментарные ателектазы, бронхообструктивный синдром, острый средний отит) зарегистрировано у $16 \%$ пациентов. Течение заболевания у всех пациентов было среднетяжелым.

Среди включенных в исследование детей у подавляющего большинства (84 \%) имелся неблагоприятный преморбидный фон, который с большой долей вероятности влиял на характер течения ВП, и только у $16 \%$ пациентов не было коморбидных заболеваний или патологических состояний, и они считались здоровыми. Из фоновых состояний следует отметить, прежде всего, высокую частоту заболеваний аллергической природы (43\%): атопического дерматита, аллергического ринита, пищевой аллергии. Как часто и длительно болеющие наблюдались $23 \%$ детей, у 18 \% были более редкие патологические состояния (дисфункция желчевыводящих путей, инфекция мочевыделительной системы и пр.). Характеристика преморбидного фона представлена на рис. 2.

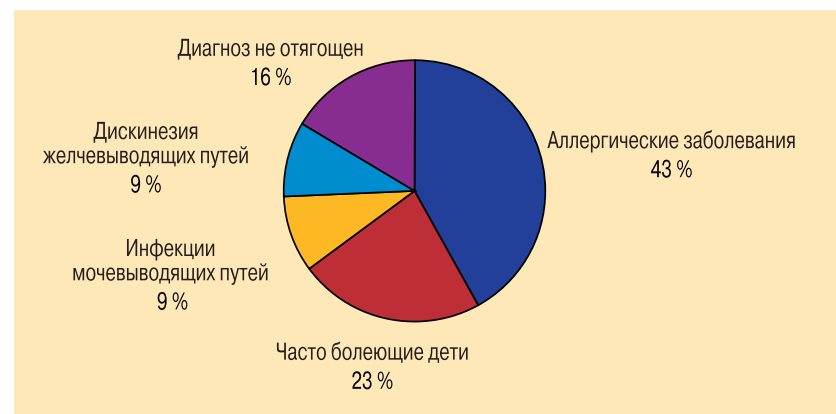

Рис. 2. Структура преморбидного фона у детей с ВП 


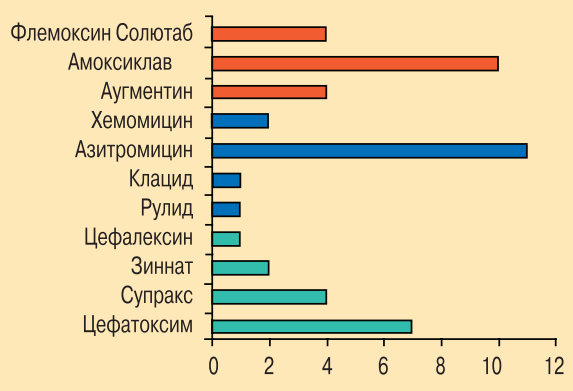

Рис. 3. Характеристика антибактериальной терапии ВП у детей

Все дети получили в амбулаторных или госпитальных условиях комплексное лечение ВП, включавшее в себя эмпирически подобранную антибактериальную терапию (рис. 3), причем его продолжительность к моменту включения в исследование у большинства больных (70,5 \%) составляла $\geq 1$ мес., что свидетельствовало о тенденции к затяжному течению бронхолегочного процесса.

Следует отметить, что при лечении детей с ВП в амбулаторных условиях использовались преимущественно антибиотики-пенициллины (Амоксиклав, Аугментин, Флемоксин Солютаб - у 36,4 \%) или макролиды (Хемомицин, Азитромицин, Клацид, Рулид - у 34,1 \%). При лечении в стационаре предпочтение отдавалось цефалоспоринам: Цефалексину, Зиннату, Супраксу, Цефатоксиму (29,5 \%). Антибактериальная терапия у 30 \% пациентов включала в себя несколько курсов антибактериальных препаратов. В патогенетическом и симптоматическом лечении ВП применялись мукоактивные и антигистаминные препараты, ингаляционная терапия.

По завершении курса этиопатогенетического лечения ВП все дети имели отчетливую положительную динамику бронхолегочного процесса: устранялись проявления интоксикации и дыхательной недостаточности, происходило обратное развитие физикальных и рентгенологических изменений,

Таблииа 2

Характеристика периода ранней реконвалесценции $y$ детей с $B \Pi(n=44)$

\begin{tabular}{|l|r|}
\multicolumn{1}{|c|}{ Показатель } & $n(\%)$ \\
\hline Клинический симптом & 100,0 \\
\hline кашель & 90,9 \\
\hline мокрота & 79,5 \\
\hline преходящие хрипы & 9,1 \\
\hline субфибриллитет & \\
\hline Лабораторные изменения с учетом возраста детей & 32,1 \\
\hline $\begin{array}{l}\text { умеренный лейкоцитоз (> 11 × 109/л) } \\
\text { нейтрофильный сдвиг лейкоцитарной формулы }\end{array}$ & 39,4 \\
\hline $\begin{array}{l}\text { до палочкоядерных нейтрофилов } \\
\text { повышенная Соэ (> 15 мм/ч) }\end{array}$ & 78,0 \\
\hline Рентгенологические изменения & \\
\hline $\begin{array}{l}\text { остаточная пневмоническая инфильтрация } \\
\text { усиление, деформация легочного рисунка, }\end{array}$ & 21,9 \\
\hline перибронхиальные, периваскулярные изменения & 100,0 \\
\hline $\begin{array}{l}\text { реакция корней легкого } \\
\text { (нечеткость контуров, расширение и пр.) }\end{array}$ & 81,8 \\
\hline реакция плевры & 9,1 \\
\hline
\end{tabular}

Таблица 3

Характеристика степени выражсенности основных симптомов ВП в период ранней реконвалесценции до начала лечения фенспиридом

\begin{tabular}{l|c|c|c|c|c|}
\hline \multirow{2}{*}{ Симптом } & \multicolumn{5}{|c|}{ Степень выраженности } \\
\cline { 2 - 5 } & $\begin{array}{c}0 \text { баллов, } \\
n(\%)\end{array}$ & $\begin{array}{c}1 \text { балл, } \\
n(\%)\end{array}$ & $\begin{array}{c}2 \text { балла, } \\
n(\%)\end{array}$ & $\begin{array}{c}3 \text { балла, } \\
n(\%)\end{array}$ & $\begin{array}{c}4 \text { балла, } \\
n(\%)\end{array}$ \\
Кашель & $0(0)$ & $4(9,1)$ & $16(36,3)$ & $15(34,1)$ & $9(20,5)$ \\
\hline Мокрота & $4(9,1)$ & $29(65,9)$ & $11(25,0)$ & $0(0)$ & $0(0)$ \\
Хрипы & $9(20,5)$ & $22(50,0)$ & $13(29,5)$ & $0(0)$ & $0(0)$
\end{tabular}

Примечание: по шкале оценки кашля, 0 - отсутствует, 1 балл - редкий сухой, 2 балла частый сухой, 3 балла - редкий влажный, 4 балла - частый влажный; по шкале оценки мокроты, 0 - отсутствует, 1 балл - скудная, сложно откашливаемая, 2 балла - умеренное количество, 3 балла - жидкая в значительном количестве; по шкале оценки хрипов, 0 - отсутствуют, 1 балл - сухие, 2 балла - влажные.

улучшались гематологические показатели. Однако полного клинического, лабораторного и рентгенологического завершения бронхолегочного процесса не было ни у одного пациента.

Анализ периода реконвалесценции ВП выявил некоторые клинические, рентгенологические и лабораторные особенности этого этапа заболевания (табл. 2).

Наблюдение пациентов в ранний период реконвалесценции ВП свидетельствовало в пользу сохранения отдельных клинических, лабораторных и рентгенологических признаков текущего воспаления, требующего продолжения лечения, несмотря на отсутствии проявлений бактериального процесса (лихорадки, интоксикации, проявлений дыхательной недостаточности, локальных изменений в легких). Следует подчеркнуть, что прямых показаний к проведению или модификации антибактериальной терапии не имел ни один пациент, однако ее необходимость была очевидна.

В качестве противовоспалительного препарата для лечения детей с ВП был выбран фенспирид с учетом доказанного в многочисленных научных исследованиях последних лет многогранного противовоспалительного эффекта. Он назначался после завершения антибиотикотерапии в составе комплексного патогенетического, симптоматического и немедикаментозного лечения в периоде реконвалесценции ВП: в таблетированной форме или в виде сиропа (с учетом возраста ребенка), в рекомендуемой дозе 4 мг на 1 кг массы тела в сутки, с кратностью приема 3 раза в день. Продолжительность лечения составила 10 дней.

Для оценки степени выраженности ведущих симптомов ВП до начала лечения и в динамике лечебного процесса использовалась балльная система. Характеристика степени выраженности основных симптомов ВП в период ранней реконвалесценции до начала лечения фенспиридом представлена в табл. 3.

Анализ основных клинических проявлений периода ранней реконвалесценции ВП до начала лечения фенспиридом позволил выявить следующие особенности: кашель был ведущим симптомом этого периода заболевания и в разной степени выражен- 
ности отмечался у всех детей, включенных в исследование $(100 \%)$. По характеру кашля преобладали пациенты с сухим, навязчивым кашлем (36,3 \%), сопровождающимся явлениями дискринии со скудной, с трудом отделяемой мокротой $(65,9 \%)$ или полным отсутствием ее экспекторации $(9,1 \%)$, с сухими $(50 \%)$, реже влажными $(29,5 \%)$ хрипами в легКих.

\section{Результаты и обсуждение}

Противовоспалительная эффективность фенспирида оценивалась по единому протоколу согласно динамике обратного развития основных клинических проявлений остаточных воспалительных изменений ВП до приема препарата, на 3, 7 и 10-й дни лечения.

Лечебному эффекту соответствовали следующие показатели:

- обратное развитие клинической симптоматики (улучшение самочувствия, исчезновение кашля, экспекторация мокроты, субфибриллитет и пр.);

- нормализация физикальных данных со стороны бронхолегочной системы;

- нормализация лабораторных и рентгенологических показателей.

В ходе исследования оценивались также противокашлевые и мукоактивные лечебные возможности препарата, особенности его взаимодействия с другими лекарственными средствами, традиционно используемыми для патогенетического и симптоматического лечения ВП в детском возрасте, влияние его на сопутствуюшие коморбидные состояния.

Кашель по мере лечения фенспиридом постепенно ослабевал, изменялись его клинические характеристики. Так, до назначения препарата он был зарегистрирован у $100 \%$ детей, к 3-му дню терапии сохранялся у 68,2 \%, к 7-му дню - у 59,1 \% пациентов, существенно стихая к 10-му дню приема препарата $(20,5 \%)$. Динамика кашля на фоне лечения фенспиридом у детей в раннем реабилитационном периоде ВП представлена на рис. 4. Следует отметить, что у 20,5\% детей, имеющих отягощенный фон по аллергическим заболеваниям, редкое сухое покашливание сохранялось после окончания курса лечения.

Уже к 3-му дню лечения у большинства пациентов кашель стал мягче, уменьшилась его интенсив-

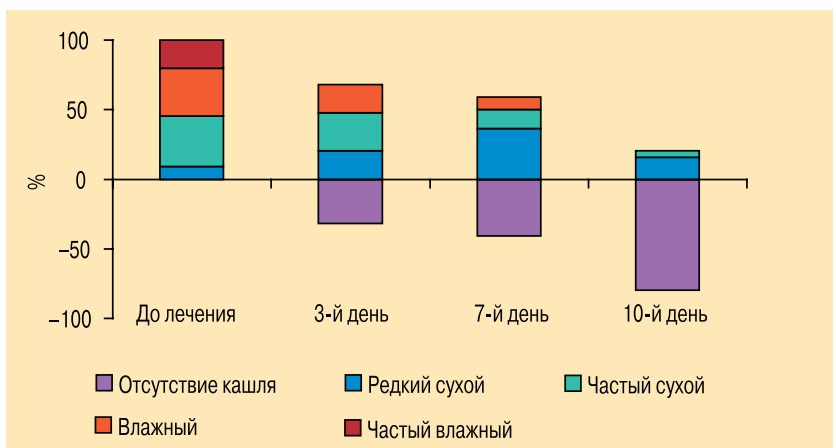

Рис. 4. Динамика кашля на фоне лечения фенспиридом детей в раннем реабилитационном периоде

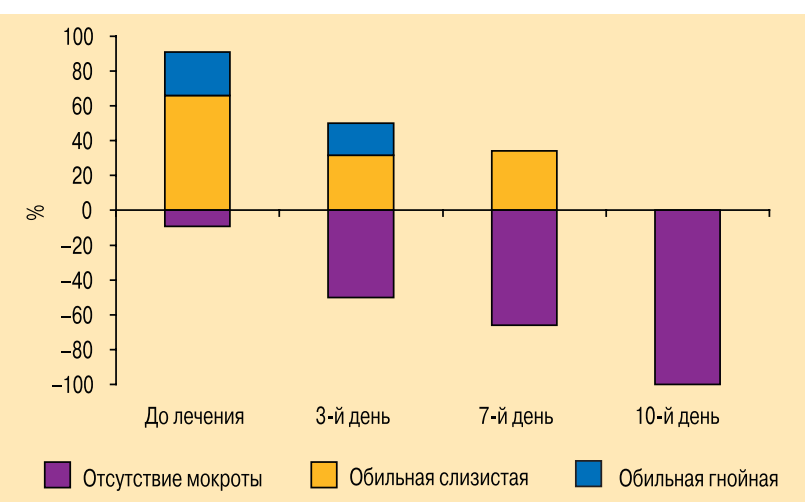

Рис. 5. Динамика экспекторации мокроты на фоне лечения фенспиридом

ность, исчезли сопутствующие симптомы: тяжесть и болезненность за грудиной, преходящие боли в животе во время кашля, неприятные ощущения при дыхании. В ходе терапии менялся и характер кашля: число детей с частым, непродуктивным кашлем снизилось до 27,2 \% к 3-му дню, до 13,6 \% - к 7-му и до 4,6 \% - к 10-му дню. Следует отметить выраженное влияние фенспирида на влажный кашель. Уже к 7-му дню лечения практически не было пациентов с продуктивным кашлем.

Наиболее заметным было изменение экспекторации мокроты (рис. 5). До начала лечения мокрота полностью отсутствовала у 9,1 \% детей при наличии сухого навязчивого кашля, а 65,9 \% пациентов отмечали сложность при откашливании скудной, вязкой мокроты. Уже к 3-му дню терапии у 54,4 \% больных мокроты не было, а 45,6 \% откашливали ее в незначительном количестве, при этом затруднений в экспекторации мокроты не испытывал ни один пациент. К 7-му дню лечения параллельно с постепенным прекращением кашля существенно уменьшилось количество пациентов, откашливающих мокроту (до $91 \%$ ), а скудное количество легко отделяемой мокроты сохранилось лишь у $9 \%$ пациентов. Такое влияние препарата на продуктивность кашля и объем мокроты можно объяснить эффектом ингибирования $\alpha_{1}$-адренорецепторов, которые стимулируют секрецию слизи.

Динамика аускультативных изменений зависела от состояния трахеобронхиальной секреции (рис. 6). До лечения фенспиридом у 50 \% пациентов выслушивались преимущественно сухие хрипы и лишь

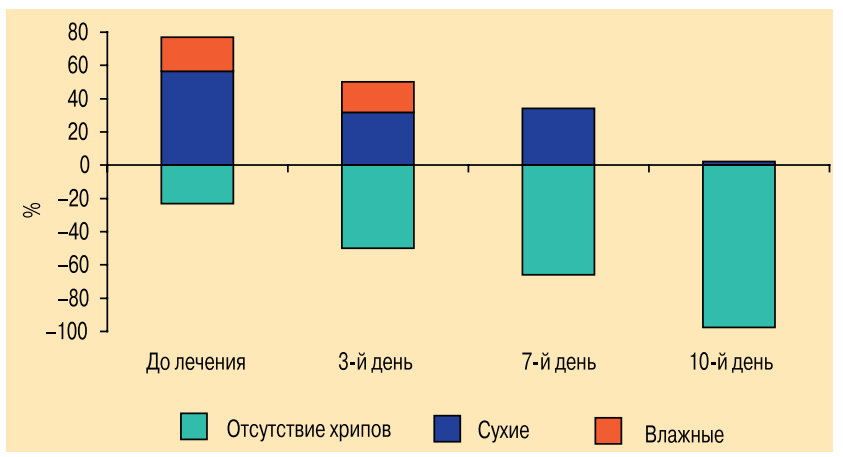

Рис. 6. Динамика аускультативных изменений в легких на фоне лечения фенспиридом 
у 29,5\% - влажные; у 20,5\% детей хрипов в легких вообще не было. В ходе терапии зарегистрировано постепенное уменьшением числа больных с хрипами. Так, к 10-му дню лечения только у 4,5 \% детей были единичные сухие хрипы в легких. Можно отметить быструю обратную динамику влажных хрипов на фоне лечения, которые не определялись ни у одного пациента уже к 7-му дню наблюдения.

На фоне лечения фенспиридом параллельно с редукцией клинических проявлений получена отчетливая положительная лабораторная и рентгенологическая динамика. К 10-му дню терапии у 98 \% детей полностью нормализовались гематологические показатели, а на рентгенограммах легких сохранялись лишь умеренно выраженное усиление и нечеткость легочного рисунка в области бывших пневмонических фокусов, у $9 \%$ - некоторая неструктурность правого корня легких. Нетяжелые побочные явления, возможно связанные с приемом препарата, зарегистрированы у 2 пациентов (4,5 \%) с неблагоприятным преморбидным фоном: в 1 случае - аллергическая сыпь, возникшая через несколько часов после приема препарата, в другом - крапивница, боли в животе. Побочные эффекты носили временный характер и были быстро ликвидированы посредством антигистаминных препаратов. Отрицательного лекарственного взаимодействия фенспирида с лекарствами, используемыми для комплексного лечения остаточных явления ВП у детей (антигистаминными, мукоактивными, иммунотропными), не выявлено.

Следует отметить хорошую переносимость препарата детьми раннего возраста (до 1 года) и пациентами с неблагоприятным аллергологическим преморбидным фоном или коморбидными заболеваниями, такими как атопический дерматит, аллергический ринит, бронхиальная астма.

Лечебный эффект был оценен как отличный у $60 \%$ больных, хороший - у $38 \%$ и удовлетворительный - только у $2 \%$ аллергиков. Отсутствие эффекта не зарегистрировано ни в одном случае.

Проведенное анкетирование пациентов и / или их родителей выявило удовлетворенность лечебным эффектом фенспирида, удобством его дозирования и применения.

\section{Заключение}

Таким образом, по результатам проведенного открытого многоцентрового исследования можно сделать вывод, что фенспирид в комплексном лечении раннего реабилитационного периода ВП:

- является эффективным противовоспалительным препаратом, подавляющим основные симптомы воспалительного процесса, характерные для раннего реабилитационного периода ВП;

- обладает косвенным мукоактивным и противокашлевым эффектом, связанным с подавлением воспаления и со снижением слизеобразования в дыхательных путях;

- может использоваться в качестве основного противовоспалительного препарата в лечении незавершенной ВП по окончании курса антибактериального лечения как альтернатива последнему;

- является безопасным лекарственным препаратом с незначительными побочными и нежелательными эффектами, без выраженного лекарственного взаимодействия, хорошо сочетающимся с наиболее часто используемыми в лечении ВП лекарственными средствами;

- имеет хороший профиль безопасности.

\section{Литература}

1. Сорока Н.Д., Коршунова Е.В. Анализ тенденций в динамике статистических показателей заболеваемости болезнями органов дыхания у детей Санкт-Петербурга. В кн.: Мизерницкий Ю.Л. и Царегородцев А.Д. (ред.) Пульмонология детского возраста: проблемы и решения. М.; 2009; вып. 9: 171-176.

2. Чучалин А.Г., Синопальников А.И., Страчунский Л.С. и др. Внебольничная пневмония у взрослых: Практ. рекомендации по диагностике, лечению и профилактике: Пособие для врачей. М.; 2005.

3. Клячкин Л.М. Принципы реабилитации больных пневмонией. Пульмонология 1997; Прил.: Пневмония: Актуальная проблема медицины: 58-64.

4. Evrard Y., Kato G., Bodinier M.C. et al. Fenspiride and inflammation in experimental pharmacology. Eur. Respir. Rev. 1991; 1 (2): 93-100.

5. Середа Е.В., Розинова Н.Н., Геппе Н.А. и др. Фенспирид (Эреспал) в терапии бронхитов у детей. 2001.

6. Сорока Н.Д. Бронхиты у детей. Пособие для врачей. СПб.: Изд. дом СПбМАПО; 2006. 77-81.

7. Дроздова М.В., Полевщиков А.В., Рязанцев С.В. Высокая клиническая эффективность Эреспала при лечении заболеваний верхних дыхательных путей. Новости оторинолар. и логопатол. 1999; 2.

\section{Информация об авторах}

Сорока Наталья Дмитриевна - к. м. н., доцент кафедры педиатрии № 1 Санкт-Петербургской медицинской академии последипломного образования, главный детский пульмонолог Комитета здравоохранения Санкт-Петербурга; тел.: (812) 717-77-28; e-mail: sorokand@mail.ru Коршунова Елена Валерьевна - К. М. Н., ассистент кафедры педиатрии № 1 Санкт-Петербургской медицинской академии последипломного образования; тел.: (812) 717-77-28; e-mail: kittenspb@mail.ru

Гомозова Светлана Петровна - врач-пульмонолог амбулаторно-консультативного отделения Детской городской больницы № 19 им. К.А.Раухфуса, заслуженный врач РФ; тел.: (812) 164-99-58

Власова Татьяна Георгиевна - врач-пульмонолог Детской городской поликлиники № 12; тел.: (812) 570-12-56

Котельникова Валентина Николаевна - врач-пульмонолог Детской городской поликлиники № 8; тел.: (812) 272-13-00

Поступила 25.01.10 (с) Коллектив авторов, 2010 удк 616.24-002-053.2-085.276 